\title{
Chest trauma: A case for single lung ventilation
}

\author{
Nagaraj Pandharikar, Anil Sachdev, Neeraj Gupta, Suresh Gupta, Dhiren Gupta
}

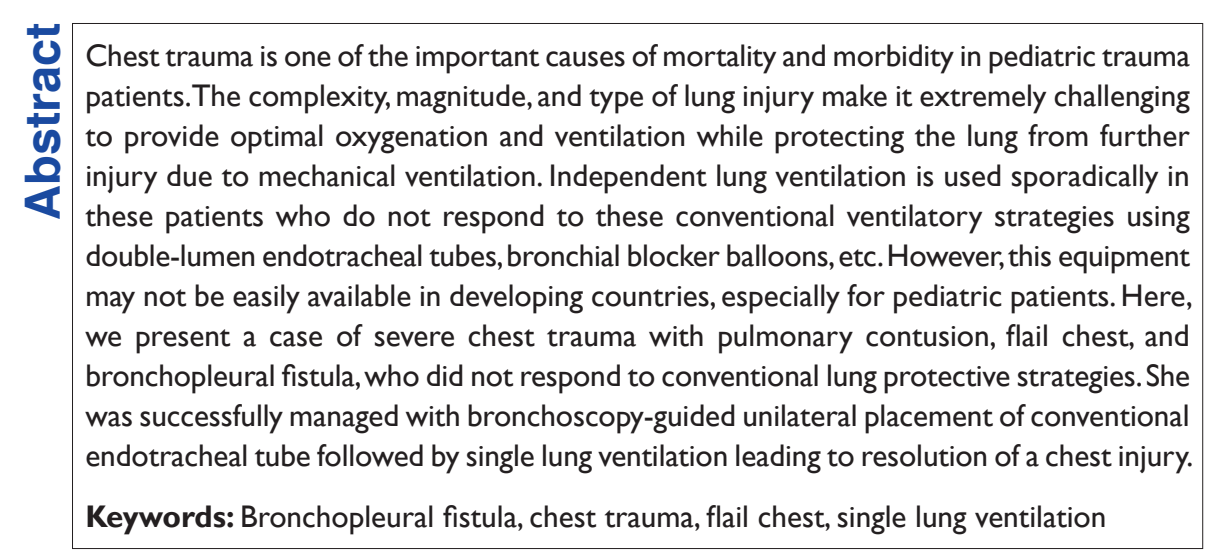

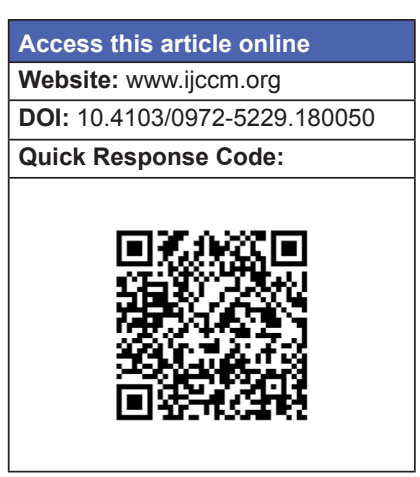

\section{Introduction}

Chest trauma accounts for one-fifth of the deaths due to trauma in children. ${ }^{[1]}$ Pulmonary contusion and flail chest constitute the most severe form of lung injury, which require meticulous respiratory support. ${ }^{[2]}$ Here, we present a case of severe chest trauma who improved after single lung ventilation (SLV) using bronchoscopy-guided unilateral placement of conventional endotracheal tube.

\section{Case Report}

A 4-year-old female child presented with a history of accident with high-speed car. She was intubated and mechanically ventilated for poor respiratory efforts at a nearby hospital. Chest radiograph (CXR) showed the right-sided pneumothorax requiring intercostal drainage tube insertion. Computed tomography (CT) scan of the chest revealed right-sided hemopneumothorax, multiple displaced rib fractures ( $4^{\text {th }}$ to $9^{\text {th }}$ ribs) and extensive contusion of underlying lung. Fractures at different segments of the $4^{\text {th }}$ and $5^{\text {th }}$ ribs were the cause of flail chest. In view of the high fraction of oxygen in inspired

\section{From:}

Department of Pediatrics, Institute of Child Health, Sir Ganga Ram Hospital, New Delhi, India

\section{Correspondence:}

Dr. Anil Sachdev, Department of Pediatrics, Institute of Child Health, Sir Ganga Ram Hospital, Rajinder Nagar, New Delhi - 110 060, India. E-mail: anilcriticare@gmail.com air $\left(\mathrm{FiO}_{2}\right)$ requirement and difficult ventilation, the child was referred to tertiary care facility.

At presentation to our hospital on the $5^{\text {th }}$ day of illness (D1 of hospitalisation), the child was hemodynamically stable, with Glasgow Coma Scale of 10. She was started on continuous midazolam and fentanyl infusions. The initial mode of ventilation was pressure-regulated volume control (PRVC) with settings of positive end-expiratory pressure (PEEP) $5 \mathrm{cmH}_{2} \mathrm{O}, \mathrm{FiO}_{2} 0.8$, tidal volume $120 \mathrm{ml}$ (at $6 \mathrm{ml} / \mathrm{kg}$ ), and rate $35 / \mathrm{min}$. The plateau pressure (Pplt) was between 30 and $32 \mathrm{cmH}_{2} \mathrm{O}$ and $\mathrm{SpO}_{2}>92 \%$. CXR showed persistent right-sided pneumothorax with intercostal tube drain (ICD) in situ, multiple rib fractures from $4^{\text {th }}$ to $9^{\text {th }}$ rib with diffuse haziness of the right lung suggestive of contusion. Another ICD was inserted in the right pneumothorax which showed continuous bubbling suggestive of bronchopleural fistula. Bedside fiberoptic flexible bronchoscopy (FFB) on day 2 of admission showed

This is an open access article distributed under the terms of the Creative Commons Attribution-NonCommercial-ShareAlike 3.0 License, which allows others to remix, tweak, and build upon the work non-commercially, as long as the author is credited and the new creations are licensed under the identical terms.

For reprints contact: reprints@medknow.com

How to cite this article: Pandharikar N, Sachdev A, Gupta N, Gupta S, Gupta D. Chest trauma: A case for single lung ventilation. Indian J Crit Care Med 2016;20:248-50. 
clots, secretions, and incomplete mucosal tear on the posteromedial aspect of the right main bronchus [Figure 1].

The ventilator strategy was titrated to achieve low-tidal volume (4-6 ml $/ \mathrm{kg})$, lower and optimal PEEP (5-6 $\mathrm{cmH}_{2} \mathrm{O}$ ), with Pplt $<35 \mathrm{~cm} \mathrm{H}_{2} \mathrm{O}$ with targets of $\mathrm{PCO}_{2}<60 \mathrm{mmHg}$ and $\mathrm{SpO}_{2}>88 \%$.

Even with optimal gentle ventilation for the next 5 days, the child showed no improvement in radiological and ventilation and oxygenation status [Table 1]. Repeat contrast-enhanced CT of the chest and pulmonary angiography showed multiple lung contusions bilaterally (right > left), right pneumothorax with preserved vascularity of the right lung.

Serial FFBs through endotracheal tube were carried out for removal of clots and secretions. Selective left lung intubation was done with the bronchoscope and single lung ventilated with PRVC mode with PEEP $5 \mathrm{~cm} \mathrm{H}_{2} \mathrm{O}$, tidal volume $-4 \mathrm{ml} / \mathrm{kg}$, rate $25-30 / \mathrm{min}, \mathrm{FiO}_{2} 0.6$, and Pplt 28-30 $\mathrm{cmH}_{2} \mathrm{O}$ [Figure 2].

The child was continued to be on Single Lung Ventilation (SLV) for $72 \mathrm{~h}$ along with nonventilatory supportive therapies, during which time her $\mathrm{FiO}_{2}$ requirement decreased to 0.5, Pplt decreased to $25 \mathrm{cmH}_{2} \mathrm{O}, \mathrm{PaO}_{2} / \mathrm{FiO}_{2}$ ratio improved to 200 . There was marked radiological improvement and air drainage from ICD ceased. Repeat FFB showed complete healing of the tear. She was gradually weaned from ventilator and was successfully extubated.

\section{Discussion}

Chest trauma accounts for $14 \%$ of trauma-related mortality in children and $80 \%$ are due to blunt injury. ${ }^{[1,3]}$ The lethality of isolated chest traumas is about $5 \%$ to $8 \%$

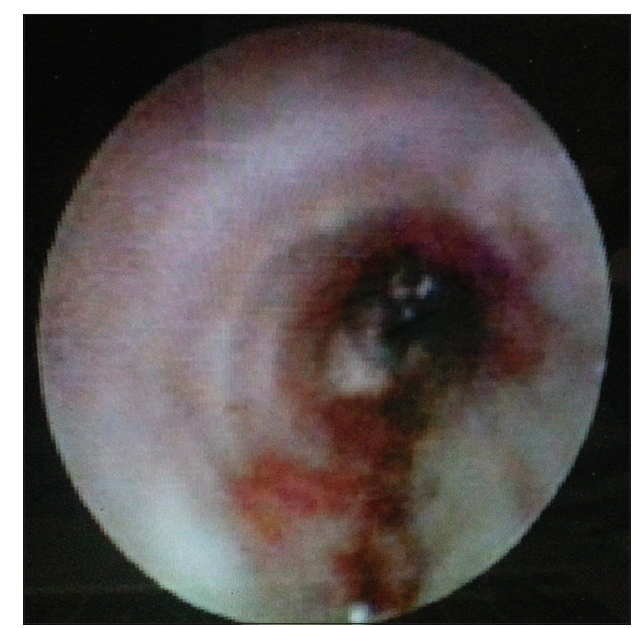

Figure I: Flexible bronchoscopic appearance of right main bronchus showing linear tear of posteromedial aspect and it increases progressively with associated injury to other body organ systems. ${ }^{[4]}$ In the pediatric patient, pulmonary contusion is the most common type present in $70 \%$ cases followed by rib fractures and pneumothorax. Injury to the mediastinal structures is rare in children. ${ }^{[5]}$ Flail chest is the most severe form of injury with high mortality. ${ }^{[6]}$ Tracheobronchial injuries mostly occur as a component of multiple traumas and $80 \%$ of ruptures are located around the carina on the right main bronchus. ${ }^{[7,8]}$

Although clinical assessment provides clues about the severity of trauma and the resultant injuries, CXR, an important initial diagnostic modality, is abnormal in $60-90 \%$ of cases but may not identify injury to mediastinal structures. ${ }^{[2]} \mathrm{CT}$ scan is the investigation of choice to detect pulmonary contusion. ${ }^{[9]}$ If necessary FFB and CT pulmonary angiography, echocardiography and electrocardiogram may provide further diagnostic information. ${ }^{[2]}$

The use of optimal analgesia and aggressive chest physiotherapy should be applied to minimize the likelihood of respiratory failure. ${ }^{[6]}$ Positive pressure provides the pneumatic stabilization, but obligatory mechanical ventilation in the absence of respiratory failure solely for the purpose of overcoming chest wall instability should

Table I: Mechanical ventilation parameters and blood gases status during Pediatric Intensive Care Unit stay

\begin{tabular}{lccccccc}
\hline Day of hospitalization & Pplt & $\mathrm{MAP}$ & $\mathrm{FiO}_{2}$ & $\mathrm{PaO}_{2}$ & $\mathrm{PaCO}_{2}$ & $\mathrm{P} / \mathrm{F}$ & OI \\
\hline DI & $3 \mathrm{I}$ & 13 & 0.8 & 81.6 & 53.2 & 100 & 12.7 \\
D2 & 30 & 14 & 0.8 & 97.8 & 56.1 & 122 & 11.4 \\
D4 & 30 & 13 & 0.7 & 77.7 & 49 & $1 \mathrm{II}$ & 11.7 \\
D6 & 30 & 12 & 0.6 & 62.4 & 50.8 & 104 & 11.5 \\
\hline
\end{tabular}

Pplt: Plateau pressure; MAP: Mean airway pressure; $\mathrm{P} / \mathrm{F}: \mathrm{PaO}_{2} / \mathrm{FiO}_{2}$ ratio, $\mathrm{PaO}_{2}$ : Partial pressure of oxygen in arterial blood; $\mathrm{FiO}_{2}$ : Fraction of oxygen in inspired air, OI: Oxygenation index; $\mathrm{PaCO}_{2}$ : Partial pressure of $\mathrm{CO}_{2}$ in arterial blood

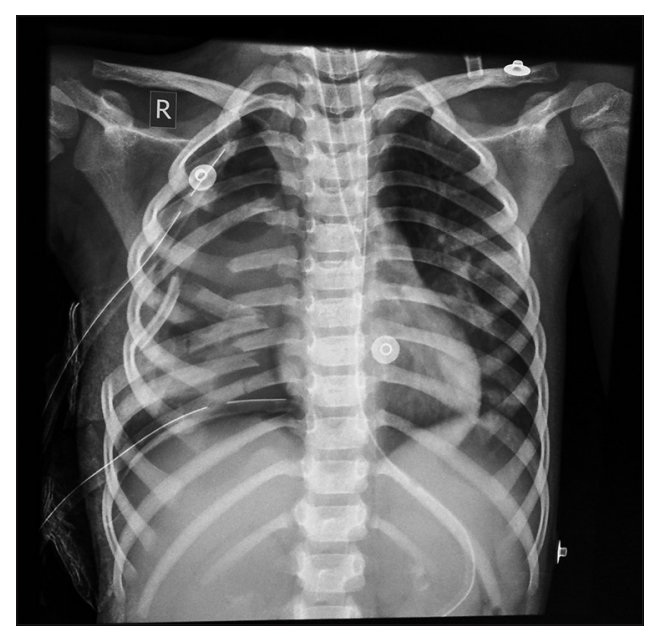

Figure 2: Chest radiograph showing selective left main bronchus intubation with multiple rib fractures, opacification of hemithorax and two intercostal drainage tube on right-sided and scattered opacities in mid and lower zones of left lung 
be avoided. Noninvasive ventilation should be considered whenever possible in conscious patients. ${ }^{[6]}$ Prevention of atelectasis and infection requires meticulous nursing care and chest physiotherapy. Frequent FFB helps sufficient removal of secretions and blood from the lungs. ${ }^{[2,10]}$

In the present case, continuous infusion of midazolam and fentanyl provided sedation and analgesia; positive pressure ventilation through endotracheal tube provided stability of flail chest segment, and repeated FFBs were done to clear clots and secretions from the airways.

High-frequency ventilation (HFV) is another mode of ventilation used mainly as a rescue mode of ventilation. Since patients with pulmonary contusion have pathology similar to acute respiratory distress syndrome, HFV with its higher mean airway pressure and lower tidal volumes achieves all the goals of lung protection by preventing cyclical de-recruitment and overdistension..$^{[1]}$ Improvement in $\mathrm{PaO}_{2} / \mathrm{FiO}_{2}$ ratio and reduced mortality were seen with use of HFV in patients with pulmonary contusion requiring higher mean peak pressure $\left(>30 \mathrm{~cm}\right.$ of $\mathrm{H}_{2} \mathrm{O}$ ) and higher $\mathrm{FiO}_{2}(>60 \%){ }^{[12]}$ In the present case, right main bronchus tear precluded the use of HFV.

Independent lung ventilation (ILV) is considered in patients with severe unilateral chest trauma in whom ventilation-perfusion mismatch is unresponsive to conventional support. ${ }^{[6]}$ Ruptures above the carina can be protected with a single- or double-lumen tube, whereas ruptures at the carina level or more distal ones make a double-lumen tube indispensable. ${ }^{[13]}$ Further distally, a univent bronchial blocker may be necessary to isolate the affected bronchopulmonary segment and to promote healing. ${ }^{[14]}$ During ILV, two separate machines are used with independent settings depending on the lung mechanics. ILV is often maintained until the disparities in lung mechanics between the injured and uninjured lung begin to resolve. Monitoring of peak and Pplts, lung compliance, and radiographic findings may guide decisions to convert to whole lung ventilation and further ventilation liberation. ${ }^{[15]}$ Surgical closure is usually necessary in unresponsive cases. ${ }^{[16]}$ In a case series by Hurst et al., ILV was initiated for 8 patients with pulmonary contusion with significant improvements in $\mathrm{PaO}_{2}$ and shunt fraction with seven patients surviving. ${ }^{[17]}$

In our case, the child continued to be on high ventilator settings, with persistent bronchopleural fistula and worsening CXR in spite of lung protective ventilator strategies on conventional ventilation, so she was considered for SLV. Due to nonavailability of double-lumen tube for our child, FFB-guided left main bronchus intubation was done. For the same reason, we used SLV instead of ILV.
The right lung oxygenation was probably provided through Murphy's eye. The child showed clinical and radiological improvement with resolution of bronchopleural fistula and pulmonary contusions. Since there are no guidelines to specify patient selection, time of initiation, ventilator settings, and termination time for SLV or ILV especially in children, such approach may be considered on an individual basis. Further, FFB-guided unilateral placement of endotracheal tube along with lung protective strategies can be used in settings where the specialized equipment is not available.

\section{Financial support and sponsorship}

Nil.

\section{Conflicts of interest}

There are no conflicts of interest.

\section{References}

1. Cooper A, Barlow B, DiScala C, String D. Mortality and truncal injury: The pediatric perspective. J Pediatr Surg 1994;29:33-8.

2. Richter T, Ragaller M. Ventilation in chest trauma. J Emerg Trauma Shock 2011;4:251-9.

3. Bliss D, Silen M. Pediatric thoracic trauma. Crit Care Med 2002;30 11 Suppl:S409-15.

4. Smyth BT. Chest trauma in children. J Pediatr Surg 1979;14:41-7.

5. Holmes JF, Sokolove PE, Brant WE, Kuppermann N. A clinical decision rule for identifying children with thoracic injuries after blunt torso trauma. Ann Emerg Med 2002;39:492-9.

6. Simon B, Ebert J, Bokhari F, Capella J, Emhoff T, Hayward T $3^{\text {rd }}$, et al. Management of pulmonary contusion and flail chest: An eastern association for the surgery of trauma practice management guideline. J Trauma Acute Care Surg 2012;73 5 Suppl 4:S351-61.

7. Cassada DC, Munyikwa MP, Moniz MP, Dieter RA Jr., Schuchmann GF, Enderson BL. Acute injuries of the trachea and major bronchi: Importance of early diagnosis. Ann Thorac Surg 2000;69:1563-7.

8. Kiser AC, O'Brien SM, Detterbeck FC. Blunt tracheobronchial injuries: Treatment and outcomes. Ann Thorac Surg 2001;71:2059-65.

9. Omert L, Yeaney WW, Protetch J. Efficacy of thoracic computerized tomography in blunt chest trauma. Am Surg 2001;67:660-4.

10. Pauzé DR, Pauzé DK. Emergency management of blunt chest trauma in children: An evidence-based approach. Pediatr Emerg Med Pract 2013;10:1-22.

11. Hager DN, Fessler HE, Kaczka DW, Shanholtz CB, Fuld MK, Simon BA, et al. Tidal volume delivery during high-frequency oscillatory ventilation in adults with acute respiratory distress syndrome. Crit Care Med 2007;35:1522-9.

12. Funk DJ, Lujan E, Moretti EW, Davies J, Young CC, Patel MB, et al. A brief report: The use of high-frequency oscillatory ventilation for severe pulmonary contusion. J Trauma 2008;65:390-5.

13. Benumof JL, Partridge BL, Salvatierra C, Keating J. Margin of safety in positioning modern double-lumen endotracheal tubes. Anesthesiology 1987;67:729-38.

14. al Jishi N, Dyer D, Sharief N, al-Alaiyan S. Selective bronchial occlusion for treatment of bullous interstitial emphysema and bronchopleural fistula. J Pediatr Surg 1994;29:1545-7.

15. Gallagher JJ. Management of blunt pulmonary injury. AACN Adv Crit Care 2014;25:375-86.

16. Tanaka H, Yukioka T, Yamaguti Y, Shimizu S, Goto H, Matsuda H, et al. Surgical stabilization of internal pneumatic stabilization? A prospective randomized study of management of severe flail chest patients. J Trauma 2002;52:727-32.

17. Hurst JM, DeHaven CB Jr., Branson RD. Comparison of conventional mechanical ventilation and synchronous independent lung ventilation (SILV) in the treatment of unilateral lung injury. J Trauma 1985;25:766-70. 